\title{
THE BIOCONTROL INFORMATION RESOURCE FOR ERMA NEW ZEALAND APPLICANTS (BIREA): AN EVALUATION
}

\author{
T.D. WHITE ${ }^{1}$, J.M. KEAN ${ }^{2}$ and B.I.P. BARRATT ${ }^{3}$ \\ ${ }^{1}$ AgResearch Ltd, Private Bag 3123, Hamilton, New Zealand \\ ${ }^{2}$ AgResearch Ltd, Private Bag 4749, Christchurch, New Zealand \\ ${ }^{3}$ AgResearch Ltd, Private Bag 50034, Dunedin, New Zealand
}

Corresponding author:toni.white@agresearch.co.nz

\begin{abstract}
An evaluation of the Biocontrol Information Resource for ERMA New Zealand Applicants (BIREA, http://www.b3nz.org/birea) website was undertaken. BIREA aims to assist applicants to ERMA New Zealand wishing to introduce biocontrol agents to New Zealand to submit a welldeveloped and informed application. The website also has potential for educating overseas biocontrol practitioners and the general public on biological control safety. ERMA New Zealand had received no new applications for import or release of biocontrol agents since the website went live in April 2007, so BIREA was evaluated by interviewing past applicants and key stakeholders. In addition, potential users of the site were surveyed and an analysis of internet visitors to the website was undertaken. Overall, BIREA was highly rated, and was thought to be a useful tool by past applicants and stakeholders. However, for BIREA to become an effective means of public education, adjustments to make the site 'public friendly' would be required. BIREA was accessed approximately hourly by a wide range of visitors from at least 55 countries. Keywords: Biological control agent, website, survey.
\end{abstract}

\section{INTRODUCTION}

The introduction of new organisms into New Zealand is controlled by the Environmental Risk Management Authority (ERMA New Zealand) via the Hazardous Substances and New Organisms Act 1996. The aim of the 'new organisms' part of this Act is to protect New Zealand from possible harmful biological, economic and cultural effects of introduced species, as well as considering the potential benefits of an introduction. An application to ERMA New Zealand must be made in order to introduce a new species to the country, for example as a biological control agent.

ERMA New Zealand staff always encourages applicants to consult with them before submitting an application, but a need was identified for an information tool that would enhance this relationship and ensure the quality of applications remained high. The aim of the Biocontrol Information Resource for ERMA New Zealand Applicants (BIREA) website at http://www.b3nz.org/birea is to assist applicants to use the information on the website in conjunction with ERMA New Zealand staff to produce a high quality application. In order to assess the effectiveness of BIREA for the target community and to provide feedback to the development team and funders, an evaluation of BIREA was undertaken. 


\section{METHODS}

It was not possible to directly measure the impact of BIREA on the quality of ERMA New Zealand biocontrol applications because none had been received since April 2007 when the website went live. Three alternative approaches were used: (1) interviews with people directly involved in past ERMA New Zealand applications; (2) a postal survey of the wider community with an interest in biological control; and (3) analysis of BIREA website usage statistics.

Semi-structured interviews were undertaken with six key individuals, either in person or over the telephone. These experts comprised past applicants to ERMA New Zealand for the release or containment of new biological control agents, Department of Conservation (DOC, a key stakeholder in the application process) staff, and ERMA New Zealand staff dealing directly with new applications. Some of those interviewed had contributed to BIREA with information based on their own experiences and professional knowledge.

A postal survey was undertaken to identify the usefulness of BIREA as an education tool for the wider community with an interest in biological control. Responses were sought from a wide range of the community including Maori groups, Government Departments, industry organisations, and private individuals. The survey used was developed by Muylle et al. (2004) specifically to explore website user satisfaction. Using five point Likert scales, the survey focused on the following ten areas: information relevancy; information accuracy; information comprehensibility; information comprehensiveness; ease of use; entry guidance; website structure; hyperlink connotation (clarity); website speed; and layout. Each area was assessed using 3-4 targeted questions. Respondents were also encouraged to write comments and answer open-ended questions related to the Likert scale results. A copy of the survey may be obtained on request from the corresponding author.

Visitors to the BIREA website were monitored by logging page requests, including the date and time, address, identification and port numbers of the visitor, the page requested and the previous page visited. Most of the visitors could be traced using WHOIS searches on their IP addresses, allowing them to be classified as either research, government or educational institutions, internet service providers (representing hits from private individuals or small companies) or automated search engine robots. Chi-squared tests were used to test whether page requests differed significantly from random, implying that visitors actively read through the material, and to identify which subject areas were most popular.

\section{Interviews with past applicants}

\section{RESULTS}

Experts who had applied to ERMA New Zealand on more than one occasion felt that BIREA had limited use for them and they would use the site only to search for specific references or information. However, those that had less experience felt they would use the site if they were involved in developing applications in the future. The overall feeling was that the website would be of greatest value to applicants new to the ERMA New Zealand process.

Experts thought the site held solid, relevant information that was accurate and reliable. From an expert's perspective the content of the website was easy to understand, although they acknowledged that it may be more daunting for new users with limited knowledge of the science of biological control. Nevertheless, interviewees indicated that this was the level of information that applicants would be required to work with.

\section{Postal survey}

Response rate to the postal survey was low, at 7\% (13/181), but this was not unexpected. In general, if an issue is not highly topical, interest tends to be low, resulting in a low commitment to survey participation. However, the results were sufficient to obtain a view from these groups in the community. In conjunction to this, the six experts interviewed, as well as another DOC staff member, also completed the survey. Apart from the experts, respondents had not used or seen the BIREA website previously. Survey results are summarised in Figure 1. 


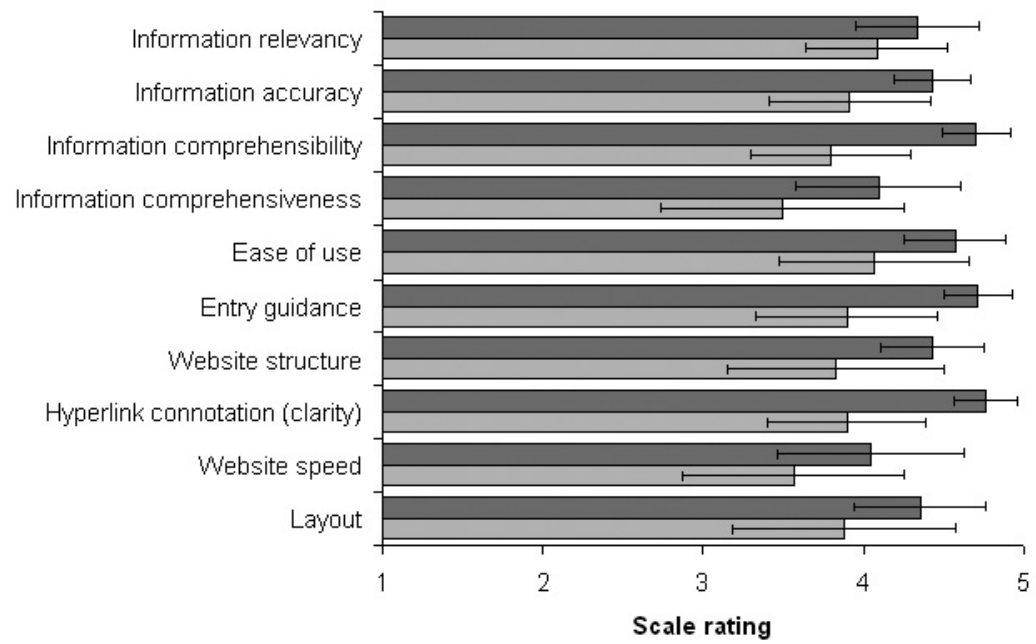

Experts $\square$ Wider community

FIGURE 1: Summary results from the postal survey on the quality of the BIREA web site. The mean response for each assessment area is shown on a five point Likert scale $(1=$ poor to $5=$ excellent $)$, together with standard error bars.

While several respondents thought information presented on the website was easy to understand and clearly presented, one respondent consistently disagreed with this point of view. A large number of neutral responses were noted regarding information comprehensibility and comprehensiveness, suggesting an overall lower level of comprehension of the collated material. Overall, the information contained in BIREA was perceived to be reasonably relevant and accurate. Some terminology used on the site was questioned, and in general, most community respondents felt that too much information was provided. Nevertheless, the wider community reported, like the expert group, that the website was easy to use and find their way around.

While experts rated the website highly in almost all sectors, they did identify some terminology to be quite technical, but acknowledged that this was the type of wording they would expect to use in an application. Moreover, they believed that its use enabled potential applicants to become more familiar with the language around ERMA New Zealand applications. There was concern expressed by some experts that the website information needed to be kept current, and that it should be used together with communication and interaction with ERMA New Zealand.

\section{Website usage statistics}

Visitor statistics measured a total of 5735 page requests received from 55 countries during the first 104 days of website operation, averaging approximately one per hour. Of these, $51 \%$ were from search engine robots (and excluded from subsequent consideration), $16 \%$ were from known research/educational organisations and $29 \%$ were from internet service providers. The remaining $4 \%$ could not be determined. $87 \%$ of visitors arrived at BIREA via a Google search, and only $4 \%$ arrived via the link provided from ERMA New Zealand's own website. Visitor activity was significantly non-random, with the introductory, background and release sections being more popular than the post-release 
monitoring and ERMA application sections. CRIs, DOC, educational facilities, central government, iwi and some primary industry companies were all recorded as visiting the site and while the majority originated from New Zealand, overseas visitors were traced to at least 119 different research/educational organisations across 32 countries.

\section{DISCUSSION}

It should be acknowledged that the results from the page request analysis were probably influenced by the user survey, as users explored the website in order to answer the survey. However, the website recorded visitors from many organisations other than those of survey respondents, suggesting that the survey probably did not greatly influence observed page requests.

In general, the experts interviewed and surveyed felt that BIREA is a valuable tool for those people wishing to apply to ERMA New Zealand to introduce new biological control agents into New Zealand. A key factor in the credibility of the website is the considerable amount of input that many experts, including some of those surveyed, had contributed to the development and information content of BIREA. The development and design of the website captured many insights about the application process and best practice from previously successful applicants, stakeholders and ERMA New Zealand. For this reason, BIREA will be most useful for those applicants that have not previously been through the ERMA New Zealand application process, or those that have applied only a few times. These applicants should consider the website as a tool, along with consultation with ERMA New Zealand and other stakeholders, to assist them to submit a well developed, high quality application. For the more experienced applicant, the website is of lesser value.

As a secondary function, BIREA has the potential to be used as a general education tool. This is evident from the wide range of visitors, both national and international, to the site in its first 3-4 months. Should general education for the public become a more primary function of BIREA, then adjustments to make the site more 'public friendly', in both content and use, would be required especially due to the technical nature of the information.

The results from this study will be used to enhance the current structure and content of BIREA as well as guiding future material to be added to the resource.

\section{ACKNOWLEDGEMENTS}

This work was funded by New Zealand's Foundation for Research, Science \& Technology through contract CO2X0501, the Better Border Biosecurity (B3) programme (www.b3nz.org).

\section{REFERENCES}

Barratt BIP, Berndt LA, Dodd SL, Ferguson CM, Hill RH, Kean JM, et al. 2007. BIREA - Biocontrol Information Resource for ERMA New Zealand Applicants (BIREA). http://www.b3nz.org/birea/ (accessed November 2007).

Muylle S, Moenaert R, Despontin M 2004. The conceptualization and empirical validation of website user satisfaction. Information \& Management 41: 543-560. 